\title{
The discharge of patients with diabetes from Internal Medicine Units: a clinical audit
}

\author{
Andrea Montagnani, ${ }^{1}$ Laura Morbidoni, ${ }^{2}$ Tiziana Attardo, ${ }^{3}$ Davide Brancato,${ }^{4}$ Maurizia Gambacorta, ${ }^{5}$ \\ Alberto Grassi, ${ }^{6}$ Ada Maffettone, ${ }^{7}$ Roberta Re,${ }^{8}$ Daniela Tirotta, ${ }^{9}$ Mauro Campanini, ${ }^{8}$ for the FADOI Permanent \\ Area of Clinical Governance \\ ${ }^{1}$ Internal Medicine Unit, Misericordia Hospital, Grosseto; ${ }^{2}$ Internal Medicine Unit, Senigallia Hospital, Senigallia (AN); \\ ${ }^{3}$ Internal Medicine Unit, B. Lombardo Hospital, Canicattì (AG); ${ }^{4}$ Internal Medicine Unit, Civic Hospital, Partinico (PA); \\ ${ }^{5}$ Internal Medicine Unit, Media Valle del Tevere Hospital, Todi (PG); ${ }^{6}$ Internal Medicine Unit, Infermi Hospital, Rimini; \\ ${ }^{7}$ Internal Medicine Unit, Colli Hospital, Napoli; ${ }^{8}$ Internal Medicine Unit, Maggiore della Carità Hospital, Novara; \\ ${ }^{9}$ Internal Medicine Unit, Cattolica Hospital, Rimini, Italy
}

\begin{abstract}
The aim of the present study was to address it by conducting a clinical audit, one that focused on the quality evaluation of the assistance given to patients with diabetes at the moment of their discharge from hospital. The clinical audit was structured in 5 phases: i) preparation; ii) definition of criteria, indicators and standards; iii) retrospective data collection; iv) data analysis, identification of main deviations from standards; v) implementation of corrective measures. Twenty Departments of Internal Medicine from 10 Italian regions retrospectively reviewed medical reports obtaining a data collection from 1332 discharged patients with diabetes. Patients receiving instructions for home glycemic control/discharged patients, showed a mean performance $=41.6 \%$ (range: 5.0-89.9); patients receiving instructions for hypoglycemic treatment/discharged patients, $=32.4 \%$ (range: $0.0-92.1$ ); patients receiving instructions for subcutaneous insulin administration/discharged patients, $=60.4 \%$ (range: $56.5-100.0$ ); patients receiving nutritional scheme or advice/discharged patients, $=24.8$ (range: $25.4-76.6$ ); patients addressed to ambulatory control/discharged patients, $=60.7 \%$ (range: $65.6-100.0$ ); and finally patients with $\mathrm{HbA1c}$ reported in discharge report/discharged patients, $=40.6 \%$ (range: 1.75-98.0). Results confirmed that all the levels are well below $70 \%$, the acceptable level of quality. The clinical audit provided data that allows for better identification of deficient clinical behaviors and the addressing of them with specific ameliorative actions; a continuing process of check, re-check and feedback in order to further enhance the quality of assistance given to patients with diabetes discharged from hospital.
\end{abstract}

\section{Introduction}

In 2004, the Italian National Institute of Health coordinated the epidemiological QUADRI study ${ }^{1}$ involving all Italian regions in order to obtain a more accurate estimate of the quality of care delivered to patients with diabetes, assuming the patients' point of

Correspondence: Andrea Montagnani, Internal Medicine Unit, Misericordia Hospital, via Senese 131, 58100 Grosseto, Italy. Tel.: +39.0564.485165 - Fax: +39.0564.485330.

E-mail: montagnaniand@gmail.com

Key words: Diabetes; hospital discharge; clinical audit; quality.

See online Appendix for Members of the FADOI Permanent Area of Clinical Governance.

Received for publication: 20 February 2014.

Accepted for publication: 2 April 2014.

This work is licensed under a Creative Commons Attribution NonCommercial 3.0 License (CC BY-NC 3.0).

CCopyright A. Montagnani et al., 2015

Licensee PAGEPress, Italy

Italian Journal of Medicine 2015; 9:141-149

doi:10.4081/itjm.2015.486 view. The results showed how the level of care of these patients is well below the acceptable level of quality suggesting the need of new models focused on continuity of care through greater integration and coordination. In particular, two critical points were highlighted in the study: i) the transition between hospital and primary care of the patient; ii) the promotion of active involvement of the patient.

Appropriate management of the discharge of the patient represents the critical step in order to achieve a stable improvement of the disease and to prevent the complications and in hospital re-admissions. However, the importance of this pivotal phase is often neglected.

In order to address this, 20 internists from 10 Italian regions, each of whom had been specifically trained to use tools of clinical governance, as a result of their attending Clinical Governance in Internal Medicine, a $2^{\text {nd }}$ level Master Course organized by Centro di Ricerca in Economia e Management in Sanità e nel Sociale (CREMS) on behalf of the Federation of Associations of Hospital Doctors on Internal Medicine (FADOI), decided to investigate the management of the discharge of such patients by conducting a clinical audit, in order to try to improve processes and outcomes through a systematic and structured process of quality improvement. 
The decision to apply the clinical audit method in this context was supported by the demonstration of the effectiveness of this tool, particularly when applied to the setting of patients with diabetes mellitus in comparison with all other clinical conditions. ${ }^{2,3}$

Previous literature searches had shown that most published papers reported results of clinical audits concerning the management of patients with diabetes in primary care. ${ }^{4,5}$ The lack of papers that reported data on the management of discharge from hospital further encouraged the Internists to conduct the clinical audit as it would contribute to the little existing evidence available concerning this important topic.

\section{Materials and Methods}

The clinical audit was conducted at multi-center level, involving 20 Departments of Internal Medicine from 10 Italian regions, and was centrally organized by a working group composed of the above-mentioned 20 Internists. The working group also organized focusmeetings and virtual conferences (by e-mail). In order to develop consensus and to measure the level of agreement, the Delphi method ${ }^{6}$ was applied.

As with the majority of published audits, the process was structured in 5 phases, detailed below; the first two were carried out from November 2012 to January 2013.

\section{Phase 1}

In this preliminary step the topic was selected and appropriate clinical questions were defined (Table 1). The following elements were specified: patients' inclusion and exclusion criteria (Table 2), sample size, methods for data collection, construction of the case report form, and strategies for the literature search.

\section{Selection of the topic}

At the beginning of the research activity each member of the working group was free to propose is- sues to be audited in the general field of the Internal Medicine; these were chosen on the basis of frequency, cost, risk (for health care providers or patients), variability/complexity, and availability of scientific evidence. The Delphi method was applied for the final selection.

The variation of indicators among the different groups was obtained by multiple analysis of variance (MANOVA) to take into account the interaction of multiple potential confounding factors. The analysis was considered statistically significant with a $\mathrm{P}<0.05$.

\section{Sample size}

The working group calculated an adequate sample size, starting from the following assumptions: i) the expected positive average deviation has the same magnitude as the negative one (symmetric difference assumption); ii) the expected prevalence of diabetic patients is $25 \%$ and the absolute precision achieved is equal to $90 \%$; iii) and at least 60 patients per center have to be enrolled from October 1, 2012 to December $31,2012$.

This resulted in a total of 1332 discharged diabetic patients, consisting of: 669 males and 663 female with a mean age of $72 \pm 14$ years and with a diabetic history of $12.8 \pm 9.6$ years (Figure 1). Among the population, $43 \%$ had compensated diabetes (CDM) whereas $42 \%$ were classified as no-compensated diabetes (NoCDM). The remaining population were affected by diabetes of new diagnosis (NDM) in $8 \%$ of cases or presented a hyperglycemia of new diagnosis (NHyp) in 7\% (Figure 2). Information about the discharge therapy showed that $33 \%$ and $35 \%$ of patients were treated respectively with oral anti-diabetic drugs or subcutaneous insulin, whereas a combination of these two therapies was found in $11 \%$ of cases. Diet only was the treatment advised for $20 \%$ of patients (Figure 3).

All considered indicators showed lower performance than the desirable standard (Figure 3).

Table 1. Selected and appropriate clinical questions to define the topic.

Management of the patient with diabetes discharged from the Department of Internal Medicine with insulin therapy

Management of the patient with diabetes discharged from the Department of Internal Medicine with therapies that may induce hypoglycemia

Non-pharmacological management (diet, follow-up outpatient) of the diabetic patient discharged from the Department of Internal Medicine

Table 2. Inclusion/exclusion criteria.

\begin{tabular}{l}
\hline Inclusion criteria \\
\hline Patients with diabetes mellitus type 1 and 2 known irrespective of the degree of compensation \\
\hline Patients with hyperglycemia (fasting blood glucose $\geq 126 \mathrm{mg} / \mathrm{dL}$ and, if not fasting, $\geq 200 \mathrm{mg} / \mathrm{dL}$ )
\end{tabular}




\section{Data collection}

The medical records of discharged patients with diabetes or hyperglycemia admitted during the three months prior to December 31, 2012 were retrospectively analyzed. Data collection started from January 1, 2013 and was completed within 5 weeks. Each member of the working group collected the data in their own center by filling out a non-electronic form for each patient. At the end of the collection period all data were transformed into an excel file that had been centralized by e-mail.

\section{Literature search}

A systematic search of Medline was conducted using a sensitive strategy (Table 3 ).

Guidelines were investigated and found in the dedicated databases. ${ }^{7}$ Finally, two guidelines were selected $^{8,9}$ and a consensus document elaborated by three Italian Scientific Societies: FADOI, Associazione Medici Diabetologi (AMD), and Società Italiana di Diabetologia (SID). ${ }^{10}$

\section{Phase 2}

Based upon the recommendations of the selected guidelines, the working group defined criteria, indicators and standards (Table 4).

\section{Phase 3}

The evaluation of clinical practice was retrospectively performed by consulting the medical records of discharged patients.

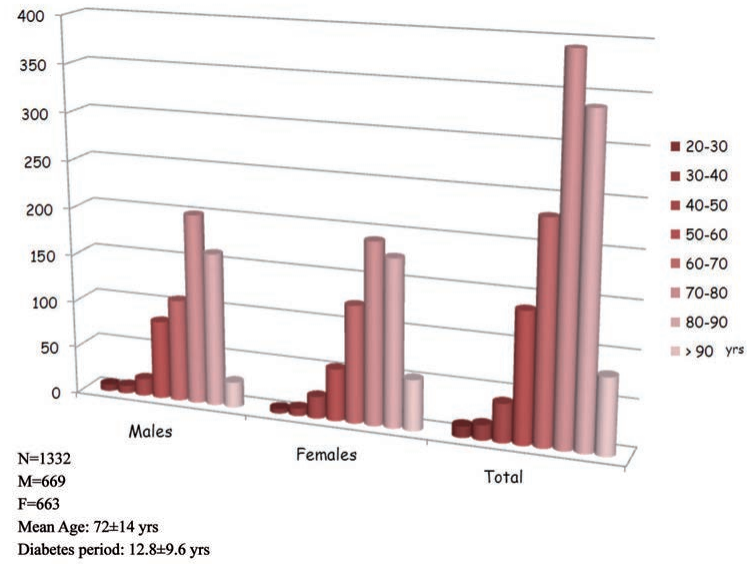

Figure 1. Distribution of study population.

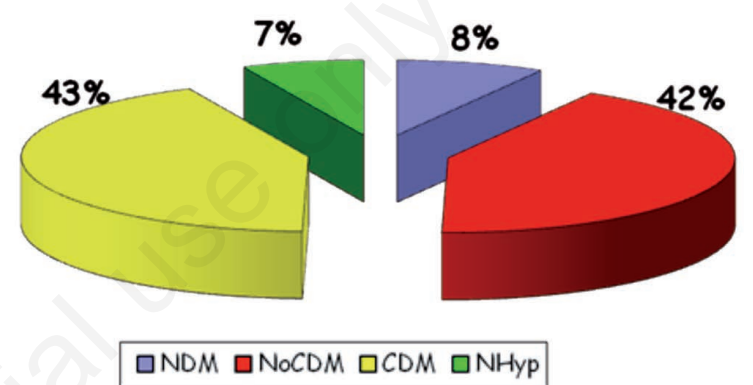

Figure 2. Distribution of patients on the basis of diabetes control. NDM, new diagnosis diabetes; NoCDM, no-compensated diabetes; CDM, compensated diabetes; NHyp, hyperglycemia of new diagnosis.

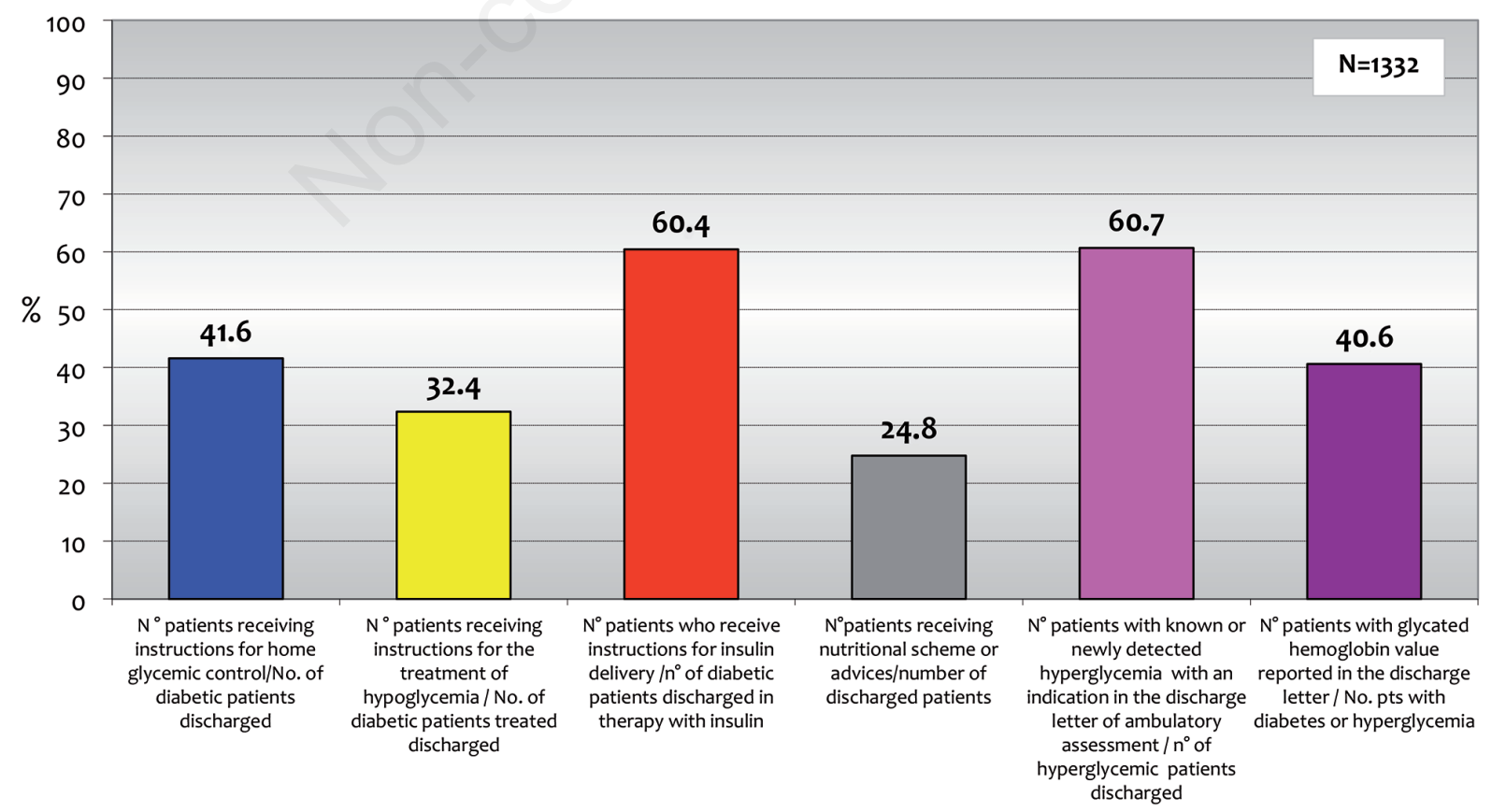

Figure 3. All considered indicators in the population. 


\section{Phase 4}

This step consisted in the analysis of the results. The analysis was conducted in each center, by comparing the results found for each indicator with the standards. Local results were then summarized and centralized to calculate the overall results for each indicator. The final results were discussed in order to identify the more deficient areas and to plan any actions aimed to improve the actual situation.

\section{Phase 5}

A number of tools were constructed, aimed at enabling and facilitating an improvement in the quality of care. In particular, the working group planned meetings in each center, to educate stakeholders (doctors and nurses) regarding the clinical audit objectives, to discuss the results, and to move doctors and nurses toward an improvement in their behavior. An information leaflet for patients was also prepared to be given

Table 3. Pubmed search.

\begin{tabular}{|c|c|c|}
\hline Search strategy & Number of records retrieved & Number of records selected \\
\hline $\begin{array}{l}\text { "Diabetes Mellitus”[Majr] AND (Practice Guideline[ptyp] AND } \\
\text { "2007/11/27”[PDat] : “2012/11/25”[PDat] AND “adult”[MeSH Terms]) }\end{array}$ & 11 & 2 \\
\hline
\end{tabular}

Table 4. Criteria, indicators and standards.

\begin{tabular}{|c|c|c|c|}
\hline Criteria & Indicators & Standard & Sources \\
\hline $\begin{array}{l}\text { 1. In patients with diabetes, undergoing therapies } \\
\text { that can potentially induce hypoglycemia, blood } \\
\text { glucose self-control, shared with the health care } \\
\text { team, is an indispensable component of the man- } \\
\text { agement of diabetes, to achieve therapeutic goals } \\
\text { and to reduce the risk of severe hypoglycemia. } \\
\text { (Level of evidence VI, Strength of Recommen- } \\
\text { dation B) }\end{array}$ & $\begin{array}{l}\text { No. of patients receiving instructions for home } \\
\text { glycemic control } \\
\text { No. of patients with diabetes discharged } \\
\text { No. of patients receiving instructions for the } \\
\text { treatment of hypoglycemia } \\
\text { No. of patients with diabetes treated discharged }\end{array}$ & $90 \%$ & $\begin{array}{l}\text { Nursing record } \\
\text { Medical record } \\
\text { Discharge letter }\end{array}$ \\
\hline $\begin{array}{l}\text { 2. Hospitalization is not the most appropriate } \\
\text { time to set up an organic educational program for } \\
\text { diabetes. However, an educational intervention } \\
\text { on some key issues, such as insulin injection and } \\
\text { the principles of self-control, must be supplied } \\
\text { to the diabetic patient before discharge. } \\
\text { (Level of evidence VI, Strength of Recommen- } \\
\text { dation B) }\end{array}$ & $\begin{array}{l}\text { No. of patients receiving instructions for insulin } \\
\text { delivery } \\
\text { No. of patients with diabetes discharged in ther- } \\
\text { apy with insulin } \\
\text { No. of patients receiving devices for the admin- } \\
\text { istration of insulin } \\
\text { No. of patients with diabetes in therapy with in- } \\
\text { sulin }\end{array}$ & $80 \%$ & $\begin{array}{l}\text { Nursing record } \\
\text { Medical record } \\
\text { Discharge letter }\end{array}$ \\
\hline $\begin{array}{l}\text { 3. Patients with normal blood glucose levels or } \\
\text { diabetes should undergo an individualized med- } \\
\text { ical nutrition therapy from a dietitian or a nutri- } \\
\text { tionist, experts in medical nutrition therapy of } \\
\text { diabetes and, then, inserted into the diabetes } \\
\text { team in order to achieve therapeutic goals. } \\
\text { (Level of evidence III, Strength of Recommen- } \\
\text { dation B) }\end{array}$ & $\begin{array}{l}\text { No. of patients receiving information booklet } \\
\text { about the diet } \\
\text { No. of patients with diabetes discharged } \\
\text { No. of patients for present for medical record nu- } \\
\text { tritional advice by dietician/nutritionist } \\
\text { No. of patients with diabetes discharged } \\
\text { No. of patients receiving personalized diet at- } \\
\text { tached to the discharge letter } \\
\text { No. of patients with diabetes discharged }\end{array}$ & $70 \%$ & $\begin{array}{l}\text { Medical records } \\
\text { Discharge letter }\end{array}$ \\
\hline $\begin{array}{l}\text { 4. At discharge, all patients with new-onset or } \\
\text { noted hyperglycemia must be sent for evaluation } \\
\text { of subsequent diabetes management. } \\
\text { (Not applicable) }\end{array}$ & $\begin{array}{l}\text { No. of patients with known or newly detected } \\
\text { hyperglycemia with an indication in the dis- } \\
\text { charge letter of ambulatory assessment } \\
\text { No. of hyperglycemic patients discharged }\end{array}$ & $70 \%$ & Discharge letter \\
\hline $\begin{array}{l}\text { 5a. All patients with diabetes admitted to hospital } \\
\text { should undergo a glycated hemoglobin control if } \\
\text { there has been no control over the last 2-3 months. } \\
\text { (Grade E Recommendation) } \\
\text { 5b. If hyperglycemia is found during a hospital } \\
\text { stay, it is appropriate to carry out the determina- } \\
\text { tion of HbA1c, in order to identify a state of un- } \\
\text { diagnosed diabetes. } \\
\text { (Level of evidence V, Strength of Recommenda- } \\
\text { tion B) }\end{array}$ & $\begin{array}{l}\text { No. of patients with glycated hemoglobin value } \\
\text { reported in the discharge letter } \\
\text { No. of patients with diabetes or hyperglycemia }\end{array}$ & $100 \%$ & Discharge letter \\
\hline
\end{tabular}


to the patients at the time of discharge. In this leaflet, the diabetic patient could find information regarding the route of administration, correct storage of insulin, diet, exact definition, symptoms and treatment of hypoglycemia, as well as hyperglycemia.

A check-list was also created, to be added to the medical records of diabetic patients, one that summarized all the steps that the doctor and/or nurse should follow leading up to and including the time of discharge. This checklist was to be an essential part of the medical record of each diabetic patient and would also work as reminder and as tool to facilitate a reaudit and the subsequent calculation of the indicators.

Finally, a re-audit was planned for September, 2013 in order to check the quality improvement achieved and to confirm the validity of the clinical audit and the tools selected implementation.

\section{Results}

On the basis of national and international guidelines, six indicators were identified. As previously explained, each Internal Medicine Units retrospectively reviewed medical reports at monthly intervals obtaining a data collection from 1332 discharged patients with diabetes; 669 males and 663 female with a mean age of $72 \pm 14$ years and with a diabetic history of $12.8 \pm 9.6$ years (Figure 1). Among the diabetic population, $43 \%$ had CDM whereas $42 \%$ were classified as NoCDM. The remaining population were affected by diabetes of NDM in $8 \%$ of cases or presented NHyp in 7\% (Figure 2). Information about the discharge therapy showed that $33 \%$ and $35 \%$ of patients were treated respectively with oral anti-diabetic drugs or subcutaneous insulin, whereas a combination of these two therapies was found in $11 \%$ of cases. Diet only was the treatment advised for $20 \%$ of patients (Figure 3 ).
All considered indicators showed lower performance than the desirable standard (Figure 3).

The first indicator, number of patients receiving instructions for home glycemic control/number of discharged patients, showed a mean performance equal to $41.6 \%$ (range: $5.0-89.9$ ). The second, number of patients receiving instructions for hypoglycemic treatment/number of discharged patients, was equal to $32.4 \%$ (range: $0.0-92.1$ ). The third, number of patients receiving instructions for subcutaneous insulin administration/number of discharged patients, was equal to $60.4 \%$ (range: $56.5-100.0$ ). The fourth, number of patients receiving nutritional scheme or advice/number of discharged patients, was equal to 24.8 (range: $25.4-$ 76.6). The fifth, number of patients addressed to ambulatory control/number of discharged patients, equal to $60.7 \%$ (range: $65.6-100.0$ ) and finally the sixth indicator, number of patients with $\mathrm{HbAlc}$ reported in discharge report/number of discharged patients, was equal to $40.6 \%$ (range: $1.75-98.0$ ).

The results may also be analyzed according to center performances. Indeed, it was considered how many centers reached the desirable standard of $70 \%$ or even better of $80 \%$ (Table 5), only a few centers achieved these standards, namely the third and the fifth indicators were equal to/over the $70 \%$ or $80 \%$ only in 30 $60 \%$ of centers, whereas for all other indicators the performances were below (Table 5).

Considering the potential influencing variables, such as the presence of a multi-disciplinary team, it was not found any significant difference between data from the 12 centers with the presence of a multi-disciplinary team and the 8 centers with the absence of such a team (Figure 4).

However, significant $(\mathrm{P}<0.01)$ differences were found between patients with NDM and NoCDM for all indicators. Comparing the CDM group with NDM group it was found that significant differences were also present.

Table 5. Centers reached the desirable standard of $70 \%$ or $80 \%$.

\begin{tabular}{lcc}
\hline Indicators & Standard $>\mathbf{7 0} \%$ & Standard $>\mathbf{8 0} \%$ \\
\hline $\begin{array}{l}\text { No. of patients receiving instructions for home glycemic control } \\
\text { No. of patients with diabetes discharged }\end{array}$ & $5 / 20(25 \%)$ & $2 / 20(10 \%)$ \\
\hline $\begin{array}{l}\text { No. of patients receiving instructions for the treatment of hypoglycemia } \\
\text { No. of patients with diabetes treated discharged }\end{array}$ & $2 / 20(10 \%)$ & $2 / 20(10 \%)$ \\
\hline $\begin{array}{l}\text { No. of patients receiving instructions for insulin delivery } \\
\text { No. of patients with diabetes discharged in therapy with insulin }\end{array}$ & $9 / 20(45 \%)$ & $7 / 20(35 \%)$ \\
\hline $\begin{array}{l}\text { No. of patients for which is present in the medical record nutritional advice } \\
\text { No. of patients with diabetes discharged }\end{array}$ & $2 / 20(10 \%)$ & $0 / 20(0 \%)$ \\
\hline $\begin{array}{l}\text { No. of patients with known or newly detected hyperglycemia with an indication in the } \\
\text { discharge letter of ambulatory assessment }\end{array}$ & $11 / 20(55 \%)$ & $9 / 20(45 \%)$ \\
$\begin{array}{l}\text { No. of hyperglycemic patients discharged } \\
\text { No. of patients with glycated hemoglobin value reported in the discharge letter } \\
\text { No. of patients with diabetes or hyperglycemia discharged }\end{array}$ & $2 / 20(10 \%)$ & $0 / 20(0 \%)$
\end{tabular}


Taking into account potential influencing factors such as age, diabetes duration, unit characteristics and others, analysis for variance among the three groups were significant for the first four indicators $(\mathrm{P}<0.01)$ but not for the last two (Figure 5).

The data were also elaborated considering surrogate parameters of workload for each Unit that is the ratio between number of hospitalizations per year/number of staff members. In the Unit with a more favorable ratio (i.e., fewer hospitalizations for each unit staff member) the indicators values were significantly higher than in those with unfavorable ratio. The trend was significant $(\mathrm{P}<0.05)$ from high to low quartile of the ratio for the indicators 1,2 , and 5 , whereas no trend was found for the others. On the other hand, dividing the whole into two groups (less or more than 150 hospitalizations for each unit staff member) it was found that all indicators values, except for that relative to HbAlc, were significantly $(\mathrm{P}<0.01)$ higher in the group with the favorable ratio in comparison with that showing unfavorable ratio (Figure 6).

\section{Discussion and Conclusions}

Diabetes is a growing global health problem, and it is predicted that $4.4 \%$ of the global population will have diabetes by $2030 .{ }^{11}$ The most recent Italian epidemiological data reported an incidence of around 500,000 new cases per year. ${ }^{12}$
Patients with diabetes are more frequently admitted to Hospital than others. It is estimated that about $25 \%$ of inpatients are affected by diabetes and that good glycemic control has a positive effect on mortality regardless of the main disease causes hospitalization. ${ }^{13-15}$ However, the care of diabetic patients is complex and requires many issues, beyond glycemic control, to be addressed. A large body of evidence exists that supports a range of interventions, not only pharmacological, to improve diabetes outcomes. ${ }^{16,17}$

With regards to the management of the care for diabetic patients, this is characterized by high direct and indirect costs. Indeed, the cost for diabetic patients is around fourfold in comparison with those without diabetes. ${ }^{13}$

The management of the discharge of diabetic patients represents the critical step in achieving a stable improve of the diabetes, preventing complications and reducing hospital re-admissions with a resulting reduction of health costs. However, there is little existing evidence available concerning this important topic.

In 2004, the Italian National Institute of Health coordinated the epidemiological QUADRI study involving all Italian regions in order to obtain a more accurate estimate of the quality of care delivered to patients with diabetes assuming the patients' point of view. The results show that the level of care of these patients is well below the acceptable level of quality. ${ }^{1}$

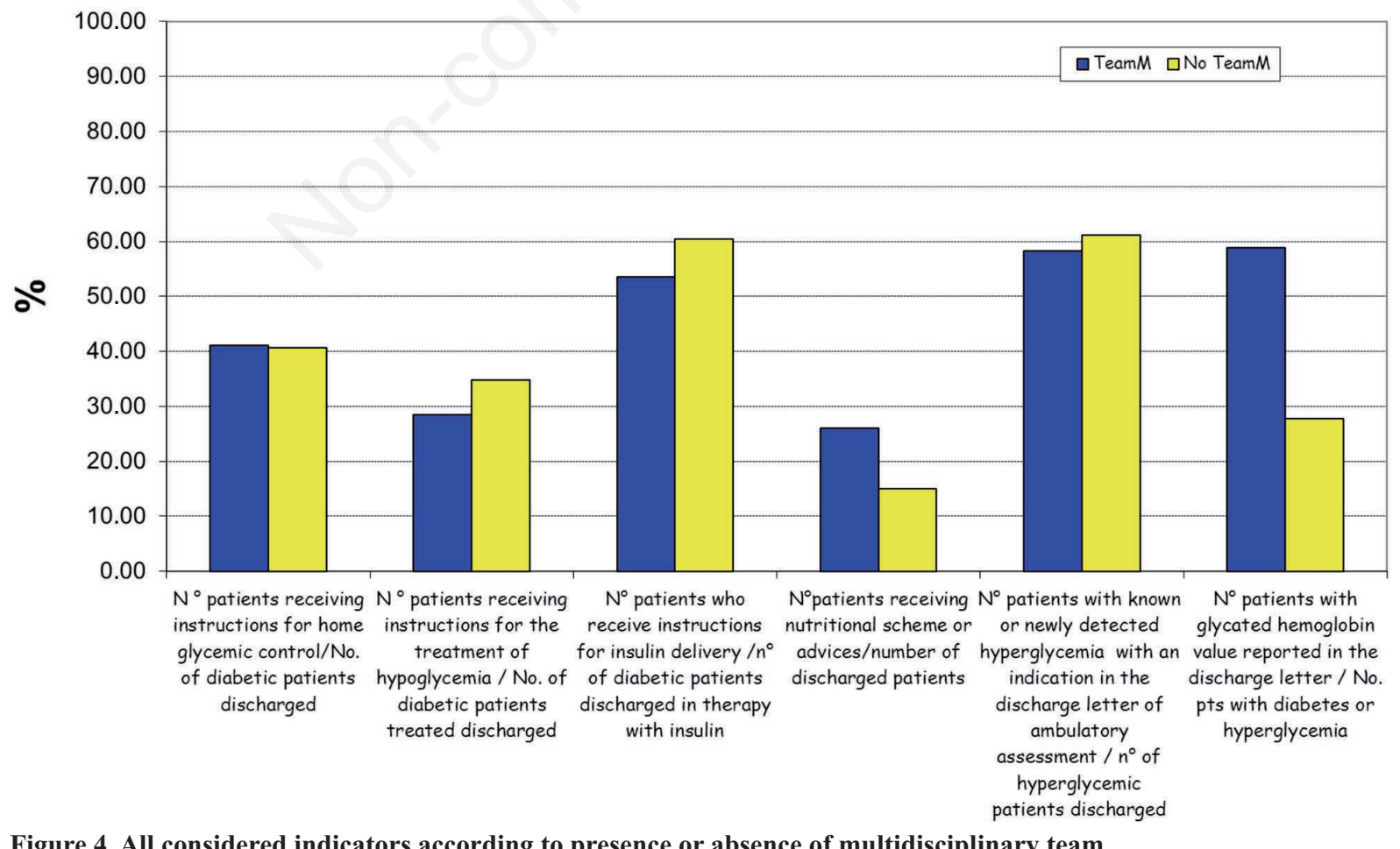

Figure 4. All considered indicators according to presence or absence of multidisciplinary team. 
A national audit, endorsed by the National Health System in 2011 showed that less than $30 \%$ of diabetic inpatients were evaluated by a diabetologist, a figure dedicated mainly to outpatients than inpatients management ( $40 \%$ vs $11 \%$, respectively). ${ }^{18}$

The multi-centered clinical audit conducted in this study showed some interesting points regarding the management of the diabetic patients' discharge from Internal Medicine Units.

The value of all indicators, calculated as mean of the results of each center before implementing improvement, did not reach the standards decided a priori whereas now, considering each center singularly, most of Internal Medicine Units reach the desirable standard for each indicator. These data suggest that the current guidelines are not only poorly applied in clinical practice by the single health professional, but also that the professionals are not used to declining practice guidelines in clinical pathways in order to guarantee the continuum of care.

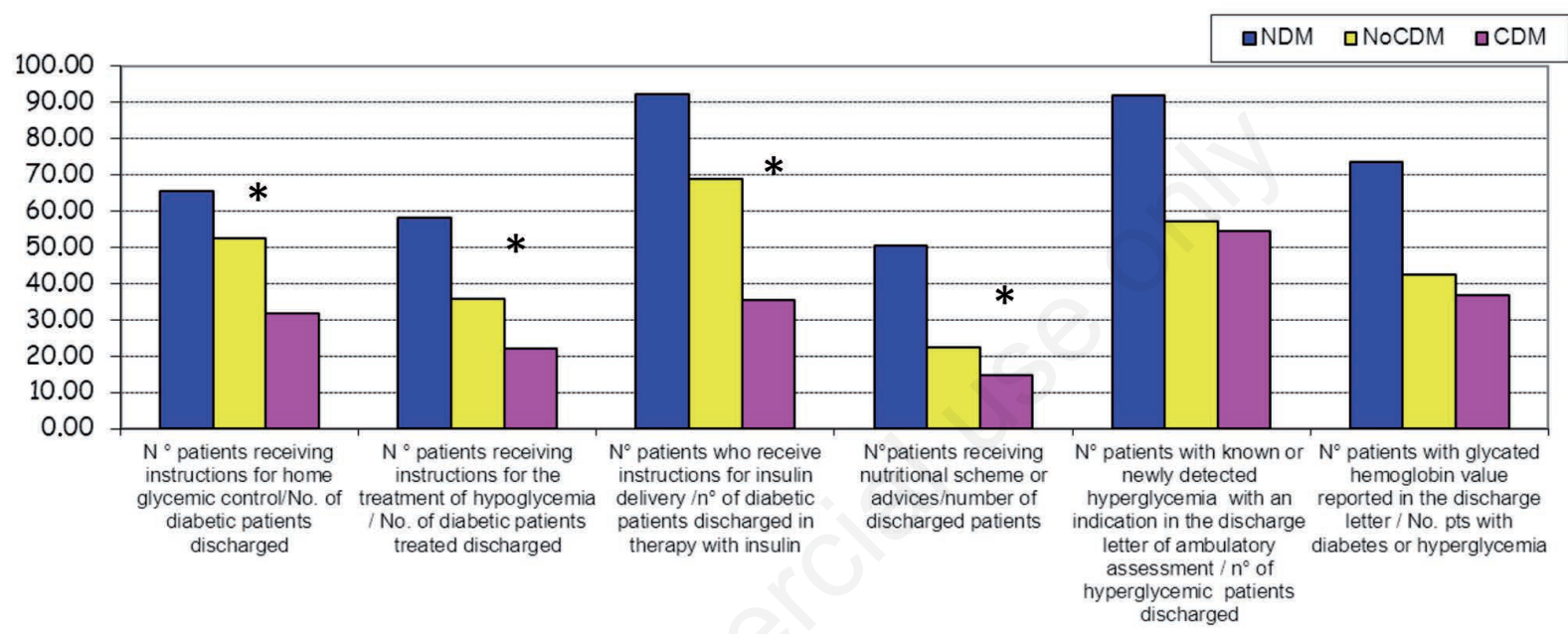

Figure 5. All considered indicators according to diabetes control. NDM, new diagnosis diabetes; NoCDM, no-compensated diabetes; CDM, compensated diabetes. * $\mathbf{P}<0.01$ by MANOVA adjusted for age, diabetes time, unit characteristics.

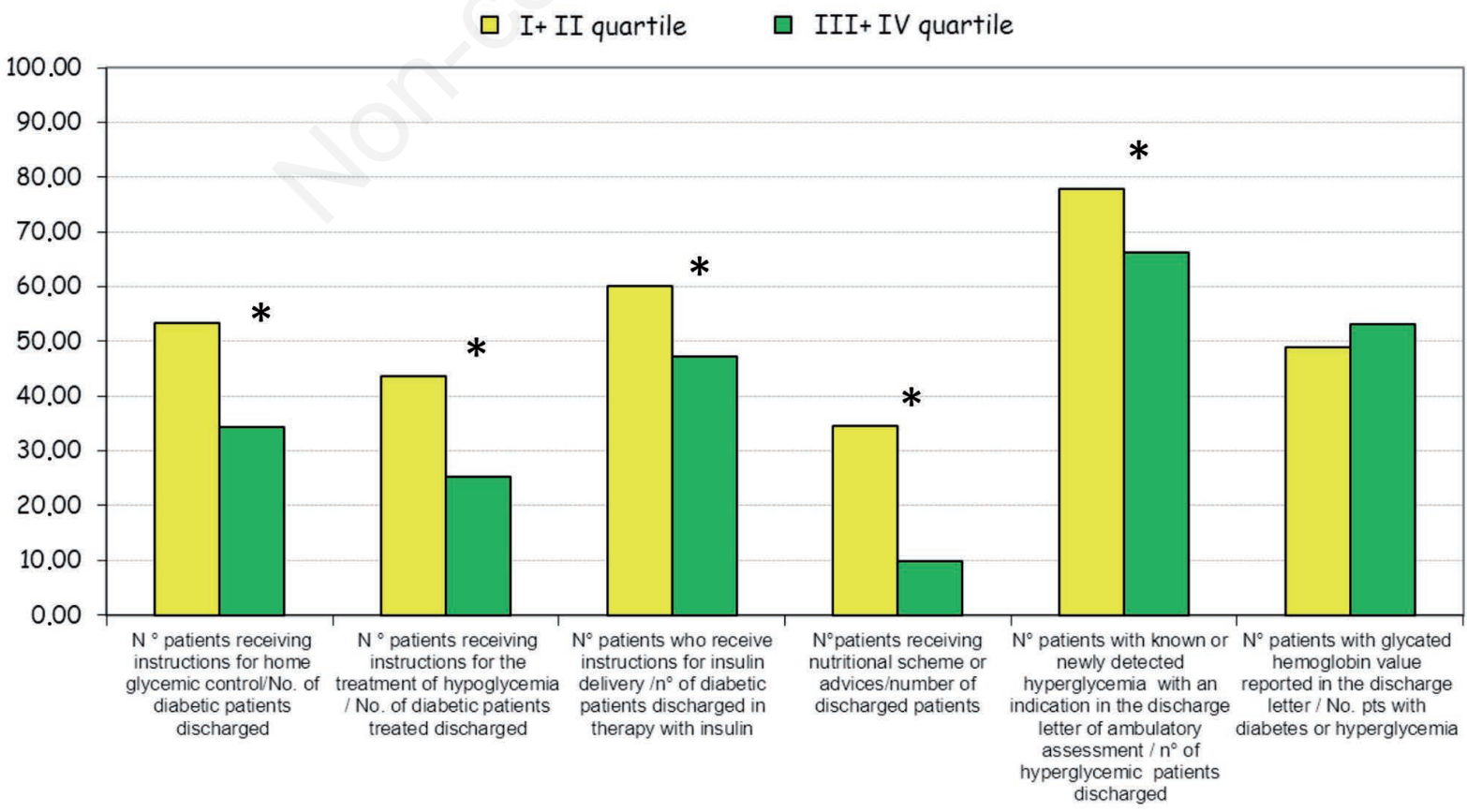

Figure 6. All considered indicators according to Unit workload. ${ }^{*} \mathbf{P}<0.05$ by MANOVA adjusted for age, diabetes time. 
More impressive, was the performance of indicator relative to nutritional advice for diabetic patients; the mean value of which was equal to $25 \%$, with only 5 out of 20 Units satisfying the standard. This result should improve, considering a recent demonstration of efficacy of education, comparable to an intensive lifestyle intervention among overweight or obese patients with type 2 diabetes. ${ }^{19}$

The clinical audit also pointed out the performance heterogeneity of the selected indicators not only among different Units, but also within the same Unit; this suggests a partial adherence to clinical guidelines.

Furthermore, the performance differences among Units may be related not only to the different implementation of clinical guidelines, but also to the differences in human resources, in organization, and to the diffusion of clinical governance tools. Indeed, by regrouping the Units into four homogenous groups, it was found that some of the indicators showed the best performances in the group with a more favorable workload/human resources ratio, suggesting that the implementation of any recommendation, requiring change of behaviors, needs time to be adopted and that this could lead to more difficulties in Units with fewer human resources.

The presence in a hospital of a multi-disciplinary team, dedicated to the management of the diabetic patient, might seem related to a higher level of expertise and implementation of the scientific evidence. However, the clinical audit did not identify differences in performance of any indicators whether there was the presence of such a team or not, suggesting the effective management of diabetic patients discharge may be possible by an internist.

Data suggest that all indicators showed better performance when diabetes is the main cause of the admission rather than when diabetes is a comorbidity and/or when it is not compensated. This showed prompt reflection on the need to pay attention also to patients with diabetes with comorbidities and to patients with diabetes that is compensated in order to improve the prognosis of such patients during their hospitalization and to avoid re-hospitalization for diabetes related complications.

The aim of this study was to conduct a clinical audit that would have enabled the implementation of change and thus enhanced the quality of patients' health. ${ }^{20}$ Based upon the findings pointed out in the retrospective phase, the clinical audit working group developed a simple instrument that could be used to improve the management of the patients with diabetes discharge from the hospital.

The working group was encouraged by the fact that it had also provided evidence in an area where there was a lack of evidence, due in part to the fact that most of the papers reporting results of clinical au- dits concern the management of patients with diabetes in primary care. ${ }^{4,5}$

A final note; this first phase of clinical audit in the discharge management of diabetic patients should be considered an important, but partial result as the primary objective of the present project was only to implement the positive change and stabilize it over time. Therefore, it is suggested that the clinical audit group carries out at least two further revision phases within the next twelve months.

\section{References}

1. Aprile V, Baldissera S, D'Argenzio A, et al. [The results of the QUADRI survey: the quality of care for diabetic persons in Italian Regions.] (Rapporti ISTISAN 07/10). Roma: Istituto Superiore di Sanità; 2007. [In Italian] Available from: http://www.iss.it/binary/publ/cont/07 10.1184843296.pdf

2. Foy R, Eccles MP, Jamtvedt G, et al. What do we know about how to do audit and feedback? Pitfalls in applying evidence from a sistemic review. BMC Health Serv Res 2005;5:50.

3. Ivers N, Jamtvedt G, Flottorp S, et al. Audit and feedback: effects on professional practice and healthcare outcomes. Cochrane Database Syst Rev 2012;6:CD000259.

4. Kamien M, Ward A, Mansfield F, et al. Type 2 diabetes. Patients practices, and satisfaction with GP care. Aust Fam Physician 1995;24:1043-9,1051.

5. Feder G, Griffiths C, Highton C, et al. Do clinical guidelines introduced with practice based education improve care of asthmatic and diabetic patients? A randomised controlled trial in general practice in east London. BMJ 1995;311:1473-8.

6. Quinn Patton M. Qualitative research and evaluation methods. Thousand Oaks: Sage Publications; 2002.

7. The National Guidelines Clearinghouse. Available from: http://www.guideline.gov/search/search.aspx?term=diabetes

8. Associazione Medici Diabetologi, Società Italiana di Diabetologia. Standard italiani per la cura del diabete mellito 2009-2010. Torino: Infomedica; 2010. pp 1-154. Available from: http://www.aemmedi.it/files/Lineeguida_Raccomandazioni/2010/2010-2010_linee_ guida.pdf

9. Association American Diabetes. Standard in medical care in diabetes-2012. Diabetes Care 2012;35:s11-63.

10. Beltramello G, Manicardi V, Trevisan R. Trialogue: managing hyperglycaemia in internal medicine: instructions for use. Acta Diabetol 2013;50:465-73.

11. Wild S, Roglic G, Green A, et al. Global prevalence of diabetes: estimates for the year 2000 and projections for 2030. Diabetes Care 2004;27:1047-53.

12. Consoli A, Nicolucci A, Caputo S. Italian Barometer Diabetes report 2012. L'impatto del diabete in Europa ed in Italia. Mozzagrogna, $\mathrm{CH}$ : Consorzio Mario Negri Sud; 13. Available from: http://www.ibdo.it/pdf/Barometer-diabetes-Report-2012.pdf

13. Ministero della Salute. Quaderno n. 10, Appropriatezza clinica, strutturale, tecnologica e operativa per la prevenzione, diagnosi e terapia dell'obesità e del diabete 
mellito; Luglio-Agosto 2011. Available from: http://www.quadernidellasalute.it/archivio-quaderni/10luglio-agosto-2011.php

14. Kosiborod M, Rathore SS, Inzucchi SE, et al. Admission glucose and mortality in elderly patients hospitalized with acute myocardial infarction: implications for patients with and without recognized diabetes. Circulation 2005;111:3078-86.

15. Inzucchi SE. Clinical practice. Management of hyperglycemia in the hospital setting. N Engl J Med 2006; 355:1093-11.

16. American Diabetes Association. Diagnosis and classification of diabetes mellitus. American Diabetes Association Position Statement. Diabetes Care 2011;34:S62-9.

17. Tahrani AA, Bailey CJ, Del Prato S, Barnett AH. Man- agement of type 2 diabetes: new and future developments in treatment. Lancet 2011;378:182-97.

18. Health and Social Care Information Centre. National Diabetes inpatients Audit 2011. Key findings about the quality of care of inpatients with diabetes in England and Wales - Report for the audit period 2011. Available from: http:/www.hscic.gov.uk/catalogue/PUB06279/ nati-diab-inp-audi-11-nat-rep.pdf

19. Look AHEAD Research Group; Wing RR, Bolin P, et al. Cardiovascular effects of Intensive lifestyle Intervention in type 2 diabetes. N Engl J Med 2013;369:145-54.

20. Johnston G, Crombie IK, Davies HT, et al. Reviewing audit: barriers and facilitating factors for effective clinical audit. Qual Health Care 2000;9:23-36. 